\title{
Thermal NDT research at Tomsk Polytechnic University, Russia
}

\author{
by V.P. Vavilov, A.O. Chulkov, D.A. Derusova \\ National Research Tomsk Polytechnic University, Lenin Av., 30, 634050 Tomsk, Russia, vavilov@tpu.ru
}

\begin{abstract}
The paper describes the history and the current status of research at Thermal NDT laboratory, Tomsk Polytechnic University, Russia. The emphasis is made on advanced modeling and data processing.
\end{abstract}

\section{Introduction}

In 1972, one of the authors (Vavilov) graduated from Tomsk Polytechnic University with a MS degree on thermal nondestructive testing (TNDT) and established the TNDT laboratory. Initially, the Tomsk research in this area was inspired by some published papers [1, 2] being mainly limited with theoretical investigations. Since that period of time, the modeling issues have become an essential part of the research; thus, the first paper published in 1973 introduced the approach which later became ubiquitous, namely, a temperature signal caused by a hidden defect is being calculated as a difference between the corresponding heat conduction solutions in the defect and non-defect areas [3]. As a result of the initial research, the importance of $2 \mathrm{D}$ and $3 \mathrm{D}$ numerical solutions became evident. The first deep analysis of $3 \mathrm{D}$ solutions was made by Vavilov and Taylor at Manchester University, UK, in 1982 [4]. It is interesting to note that, when solving multi-dimensional TNDT problems in that period, the computation time reached some minutes on the world most powerful CDC 7600 computer. A very similar research was done in parallel by MacLaughlin and Mirchandani in the USA [5]. It is worth mentioning that, in the 1970-1980s, the theory, hardware and methodology of TNDT were intensively developing by Carlomagno and Berardi [6], Busse [7], Balageas et al. [8], Maldague [9], Burleigh [10].

In the USSR, hardware development in the 1980s was related to the fact that the only foreign supplier of infrared (IR) cameras was AGA (later AGEMA), Sweden, and the cost of the equipment was too high to become a conventional research and/or industrial tool. A number of Soviet IR imagers (called in Russian "teplovisors") were developed following three research directions: 1) copying Western equipment, 2) developing original concepts of IR vision, and 3) developing simplified versions of "teplovisors". However, it was quickly understood that, for example, a temperature resolution of IR imagers is not a crucial factor in detecting and identifying subsurface defects (see the humorous TNDT laws suggested by the authors in Appendix).

By the end of the 1980s, i.e. at the eve of "perestroyka", the staff of Tomsk laboratory of TNDT reached 25 employees, and the most of research was done for military and space applications. In that time, the Tomsk laboratory was developing a concept for the remote evaluation of water content in tiles of Buran space shuttle thermal protection. Two examples of home-made equipment developed at that period of time are shown in figure 1.

The period from 1990 to 2010 was marked by intensive international collaboration of Tomsk Thermal NDT laboratory with many known TNDT experts/teams: Maldague (Canada) [11], Grinzato, Bison and Marinetti (Italy) [12], Thomas et al., Burleigh (USA) [13, 14], Lahiri et al. (India) [15], Guo Xingwang (China) [16], Swiderski (Poland) [17], Kauppinen (Finland) [18].

\section{Current status}

A summary of current TNDT research at Tomsk Polytechnic University is presented in table 1. 


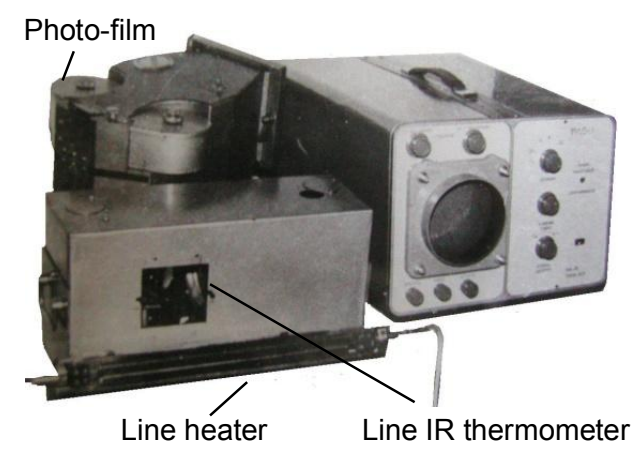

Parker's temperature profile; it was found that thermal diffusivity of cutting tools is related to their wear resistance.

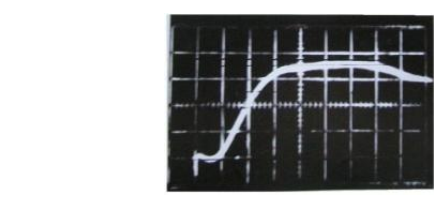

He-Ne laser Powerful pulsed laser

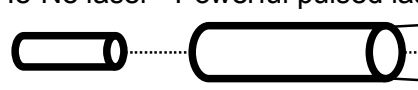

$$
\text { b) }
$$

a)

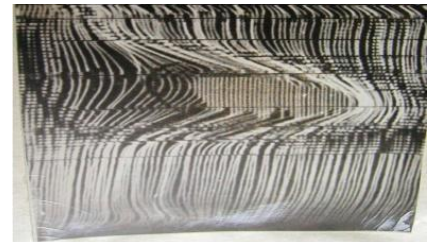

Temperature distribution (defect indication in centre)

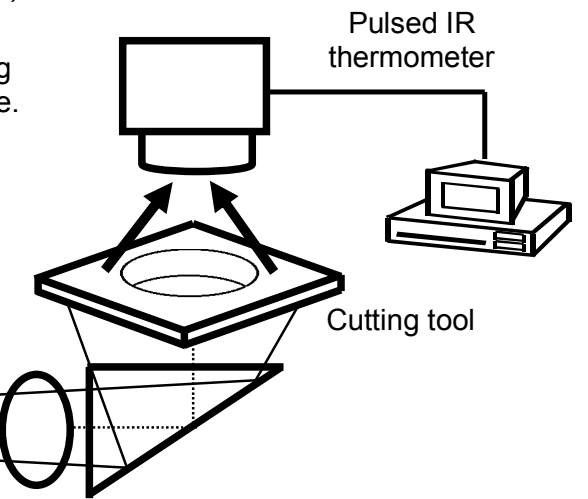

Fig. 1. Specialized TNDT equipment, Tomsk Polytechnic University:

a - photo-recording IR device for active TNDT of soldered joints in large-size two-layer metallic cylinders (1980),

$b-T N D T$ device for inspecting cement carbide cutting tools (1994)

Table 1. Thermal NDT research at Tomsk Polytechnic University

\begin{tabular}{|l|l|l|}
\hline \multicolumn{1}{|c|}{ Research area description } & Modeling TNDT problems \\
\hline $\begin{array}{l}\text { Multilayer is a basic program for analytical } \\
\text { modeling heat conduction in 3-layer plates, } \\
\text { where the central layer can represent } \\
\text { either a bonding structure, or a defect } \\
\text { (laterally-extended defects are assumed). }\end{array}$ \\
$\begin{array}{l}\text { The difference between the corresponding } \\
\text { solutions as a function of time is a result of } \\
\text { calculation. Program has been used for } \\
\text { verification of 2D and 3D numerical } \\
\text { solutions. }\end{array}$
\end{tabular}


ThermoCalc-2D is a basic program for the numerical modeling $2 \mathrm{D}$ heat conduction in 3-layer disks with disk-like defects (cylindrical coordinates) uniformly heated on the surface. Calculation results are presented as temperature evolution profiles in time and space with the automatic determination of maximum temperature signals and times of their appearance.

Simple, accurate and robust.

ThermoCalc-2DM is a version of ThermoCalc-2D, but a disk-like defect can be placed in a shell made of a different material, thus modeling, for example, a landmine in soil surrounded by thin air gaps, or a Teflon insert in a composite surrounded by modified host material.
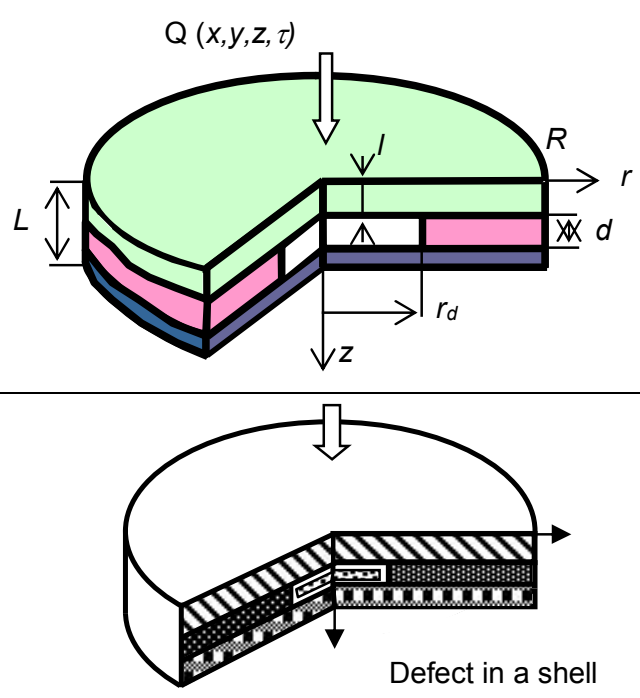

ThermoCalc-2D Build is a version of ThermoCalc-2D intended for building applications. It allows defining an arbitrary heating function and calculating both temperatures and heat fluxes density.

ThermoCalc-6L is a basic program for modeling $3 \mathrm{D}$ heat conduction in $\mathrm{a}$ parallelepiped-like 6-layer body which might contain up to 9 subsurface defects (Cartesian coordinates). The 3D nonadiabatic anisotropic problem is being numerically solved by using an implicit finite-difference method. External sample heating can be modeled with a uniform, Gaussian or spatially-arbitrary heat flux (in the last case, an experimental or calculated heat mask is being used). Calculation results are represented by $2 \mathrm{D}$ time-dependent temperature distributions on the sample surfaces or inside the sample. The Program calculates time evolution temperature profiles and determines maximum signals and times of their appearance. The results can be saved as IR image sequences or Matlab $3 \mathrm{D}$ vectors. The Program allows modeling complicated defects.

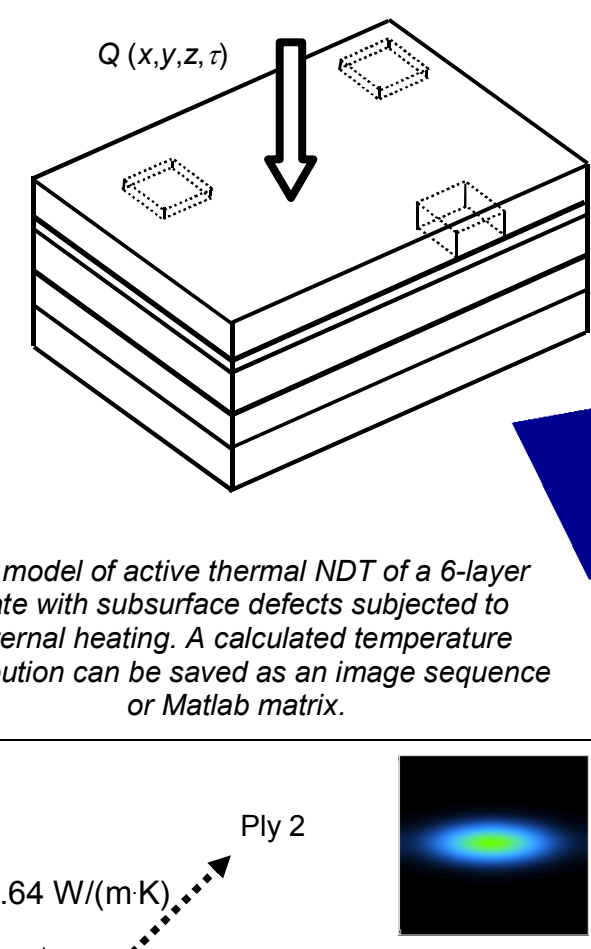

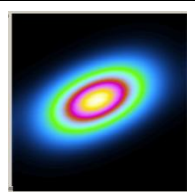

c) subsequent layer can be tilted against the previous one by a certain spatial angle, thus modeling composites with anisotropic layup of fibers.

ThermoCalc-36L is a version of ThermoCalc- $6 \mathrm{~L}$ but the number of sample anisotropic layers can reach 36 . Each

b)

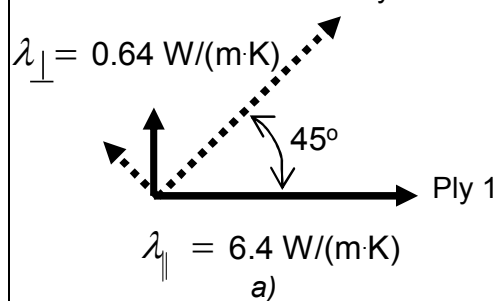

Under spot-like heating, the anisotropy of a composite with $45^{\circ}$ fiber layup (a) is clearly seen in one-layer (b) and two-layer (c) samples 


\begin{tabular}{|c|c|}
\hline $\begin{array}{l}\text { ThermoCalc Source is a version of } \\
\text { ThermoCalc- } 6 \mathrm{~L} \text { but each of } 9 \text { defects } \\
\text { simulates a heat source with a particular } \\
\text { volumic heat power. The Program was } \\
\text { designed for modeling defects in micro- } \\
\text { chips and can be used for evaluating } \\
\text { power generated by cracks under } \\
\text { ultrasonic stimulation. } \\
\text { Both additive and multiplicative noise can } \\
\text { be imposed onto calculated temperature. }\end{array}$ & $\begin{array}{l}\text { Three heat sources in a chip with no noise (a) } \\
\text { and with imposed real-chip emissivity noise (b) }\end{array}$ \\
\hline $\begin{array}{l}\text { ThermoCalc Mine is a version of } \\
\text { ThermoCalc- } 6 \mathrm{~L} \text { but it allows modeling: 1) } \\
\text { arbitrary heating function in time, 2) } \\
\text { exponential absorption of heating energy } \\
\text { in a tested material, 3) linear variation of } \\
\text { thermal conductivity across layer } \\
\text { thickness. Program was primarily } \\
\text { developed to model the detection of } \\
\text { landmines in moist soil under solar } \\
\text { irradiation. }\end{array}$ & $\begin{array}{l}\text { A heating function time profile } Q(\tau) \text { is defined in table form. Heating } \\
\text { energy } Q(z \text { is exponentially decaying with depth. Material thermal } \\
\text { conductivity } K(z) \text { varies linearly with depth. }\end{array}$ \\
\hline \multicolumn{2}{|c|}{ Processing experimental data } \\
\hline $\begin{array}{l}\text { ThermoFit Pro is the Program dedicated } \\
\text { to off-line advanced treatment of both } \\
\text { experimental and artificial IR images. The } \\
\text { Program implements the most of world } \\
\text { achievements in TNDT data processing. } \\
\text { The main processing algorithms are as } \\
\text { follows: 1) filtration in time and space, 2) } \\
\text { sequence normalization in order to } \\
\text { suppress multiplicative noise, } \\
\text { 3) suppression of additive noise, e.g. } \\
\text { conditioned by reflections, 4) polynomial } \\
\text { fitting of time evolutions, 5) Fourier time } \\
\text { analysis; obtaining phasegrams and } \\
\text { ampligrams produced at particular Fourier } \\
\text { frequencies, 6) wavelet time analysis, both } \\
\text { scalar and complex, 7) principal } \\
\text { component analysis (PCA). } \\
\text { The Program implements some unique } \\
\text { processing algorithms, namely, thermal } \\
\text { tomography, 2) 1D defect characterization } \\
\text { (to evaluate defect depth and thickness); } \\
3 \text { 3D defect characterization (this } \\
\text { technique takes into account visible lateral } \\
\text { size of defects); 4) determination of } \\
\text { material thermal properties, both effusivity } \\
\text { and diffusivity, 5) statistical analysis; } \\
\text { determining signal-to-noise ratio, } \\
6 \text { 6) corrosion characterization. }\end{array}$ & $\begin{array}{c}\text { Data processing examples in TNDT of CFRP } \\
\text { composite: a-source image, } b \text { - Fourier phasegram, } \\
\text { c-thermal tomogram of the 1.1-1.3 mm layer }\end{array}$ \\
\hline
\end{tabular}




\begin{tabular}{|c|c|}
\hline \multicolumn{2}{|c|}{ New experimental procedures in active TNDT } \\
\hline $\begin{array}{l}\text { Determining material anisotropic } \\
\text { thermal properties } \\
\text { In a two-sided test procedure, a modified } \\
\text { Parker technique is used for determining } \\
\text { three components of thermal diffusivity } \\
\left\{\alpha_{x}, \alpha_{y}, \alpha_{z}\right\} \text {. } \\
\text { A one-sided procedure is recommended } \\
\text { for the determination of lateral components } \\
\text { of diffusivity }\left\{\alpha_{x}, \alpha_{y}\right\} \text { and thermal } \\
\text { effusivity } e_{z}=\sqrt{C \rho \lambda_{z}} \text {. } \\
\text { To stimulate a test material, one may use } \\
\text { lasers and lamp heaters in combination } \\
\text { with a spot or slit mask. }\end{array}$ & $\begin{array}{l}\text { Anisotropic composite is heated through a slit-mask (a), afterwards, the } \\
\text { Fourier spectrum is being analyzed at the carrier frequency (b). Thermal } \\
\text { diffusivity is determined by each spatial coordinate by the slope of the } \\
\text { straight line that is the evolution of the logarithmic "Fourier-temperature" } \\
\text { in time (c) }\end{array}$ \\
\hline $\begin{array}{l}\text { Evaluating rear-surface corrosion } \\
\text { Both the method and the experimental set- } \\
\text { up are developed to evaluate rear-surface } \\
\text { corrosion quantitatively. }\end{array}$ & $\begin{array}{l}\text { A cylindrical sample is sequentially monitored, afterwards, a composite } \\
\text { IR thermogram (left) is converted into a binary image (right), for } \\
\text { example, by using a neural network. }\end{array}$ \\
\hline $\begin{array}{l}\text { Ultrasonic IR thermography } \\
\text { Ultrasonic stimulation is performed at the } \\
\text { frequency of } 22 \mathrm{kHz} \text {. The indentor } \\
\text { electrical power is up to } 2.5 \mathrm{~kW} \text { and the } \\
\text { duration of stimulation is from } 0.1 \text { to } 10 \mathrm{~s} \text {. } \\
\text { A defect-free material remains cold, while } \\
\text { structural inhomogeneities, in particular, } \\
\text { surface and subsurface cracks, generate } \\
\text { thermal energy due to internal friction and } \\
\text { plastic deformation. This method is } \\
\text { applicable to both metals and non-metals. }\end{array}$ & $\begin{array}{l}\text { Inspecting quality of friction stir welding of } \\
\text { aluminum, some defects are clearly } \\
\text { detected: left-source image, right- wavelet } \\
\text { phasegram }\end{array}$ \\
\hline $\begin{array}{l}\text { Induction IR thermography } \\
\text { This technique has been applied to the } \\
\text { detection of fatigue cracks in thick steel } \\
\text { samples. The heating is accomplished } \\
\text { inductively with the eddy current frequency } \\
\text { being up to } 30 \mathrm{kHz} \text { and the inductor power } \\
\text { up to } 30 \mathrm{~kW} \text {. }\end{array}$ & $\begin{array}{c}\text { Two fatigue cracks are clearly seen in the IR thermogram } \\
\text { of a rail which is moving through an inductor }\end{array}$ \\
\hline $\begin{array}{l}\text { Material fracture analysis } \\
\text { Samples under standard mechanical tests } \\
\text { are thermographically monitored with } \\
\text { simultaneous acquisition of IR image } \\
\text { sequences. The goal of analysis is to } \\
\text { predict destruction and evaluate life source } \\
\text { of (nano-) materials. }\end{array}$ & $\begin{array}{l}\text { A polycrystallic titanium reveals a single } \\
\text { powerful source of thermal energy } \\
\text { appearing in the damage area (left), } \\
\text { while nanotitanium is characterized by } \\
\text { uniform temperature increase across a } \\
\text { whole cross-section of damage (right) }\end{array}$ \\
\hline
\end{tabular}




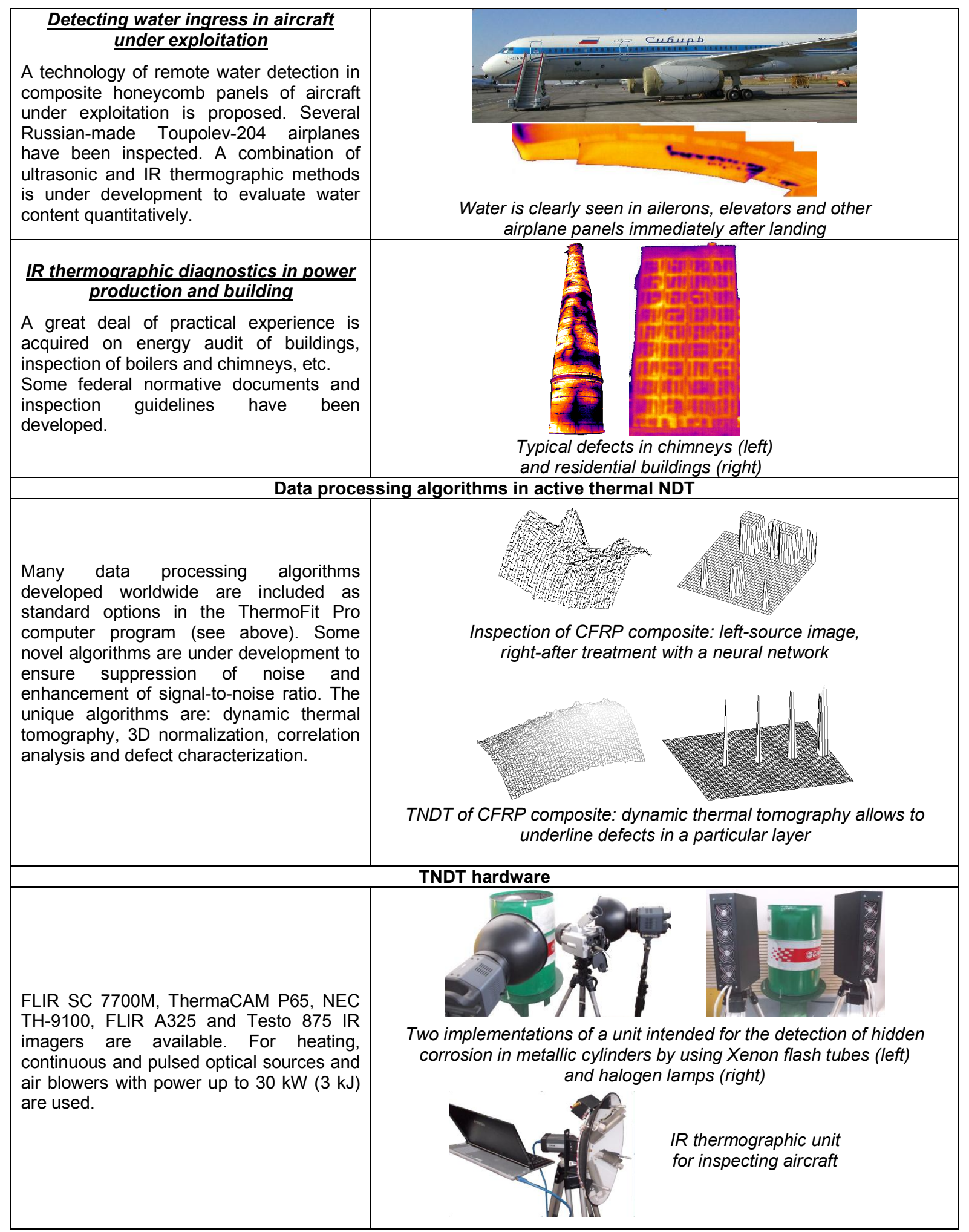




\section{Set-up for ultrasonic IR thermographic $\underline{N D T}$}

A specialized source for pulsed ultrasonic stimulation by using a magnetotostrictive indentor has been developed (ultrasonic frequency $22 \mathrm{kHz}$ with $\pm 120 \mathrm{~Hz}$ deviation, pulse duration $0.1-10 \mathrm{~s}$, electrical power up to $2.5 \mathrm{~kW}$ ).

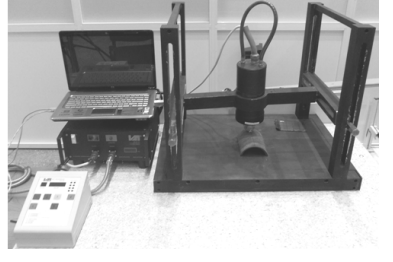

Set-up for ultrasonic IR thermographic NDT

\section{Perspective research}

In TNDT modeling, a current trend is the development of a flexible and user-friendly software package which would allow solving typical 3D TNDT problems when involving non-adiabatic (linear and non-linear) heat exchange, arbitrary heating, dependence of thermal properties on space and time, phase transformation of substances, etc.

In data processing, the emphasis will be done on the development of inverse algorithms which are to be accurate, robust and applied to all pixels in image sequences thus enabling to produce images of defect depth and thickness. Some novel approaches suggested by the Tomsk team, such as dynamic thermal tomography and one-sided determination of thermal diffusivity, will be further explored. Thermal tomography, unlike classical thermography, is a technique which enables slicing a solid by few layers due to fact that deeper layers produce front-surface signals with increasing time delay [19]. Another novel idea is to determine material diffusivity in a one-sided test by using formulas similar to Parker's one [20]. The concept is to produce an artificial function $T(\tau) \times \tau^{n}$ in each pixel, where $\tau$ is the time, and $n$ is typically from 0.01 to 0.5 . In non-defect areas, the time evolution of this function reveals a clear minimum $\tau_{\min }$ (figure 2a) where thermal diffusivity can be calculated by the expression: $a=F O_{\min } L^{2} / \tau_{\min }$, where $F_{O_{\text {min }}}$ is a function of $n$; for instance, $F O_{\text {min }}=0.2237$ for $n=0.4$ that seems to be an optimal value when determining diffusivity [20]. Over subsurface defects, the $T(\tau) \times \tau^{n}$ function behaves in a more complicated way but often reveals clear maximums, as shown in figure $2 a$. This fact can be used for developing reference-free thermal tomography (see the thermal tomogram of impact damage in CFRP in figure $2 b$ ).

Another novel research direction is the evaluation of the quality of the so-called hyper-conductive modules, or mini heat tubes (figure 3a), used for heat dumping from satellite electronic units. These modules represent a hermetic multilayer construction filled with a liquid heat carrier. Heat transfer occurs due to heat carrier phase transformation. The equivalent thermal conductivity of mini heat tubes may reach $25000 \mathrm{Wm}^{-1} \mathrm{~K}^{-1}$, and their efficiency depends on the uniformity of their structure. In our preliminary research, mini heat tubes were heated with a flash Xenon tube while the sample rear surface was monitored with a FLIR SC7700 IR imager (acquisition frequency $412 \mathrm{~Hz}$ ). By converting a sequence of source IR thermograms (figure $3 b$ ) into a map of diffusivity (figure 3c), one may efficiently evaluate the characteristics of heat conduction within mini heat tubes (note a very high diffusivity values compared to 'normal' solids, both metals and non-metals).

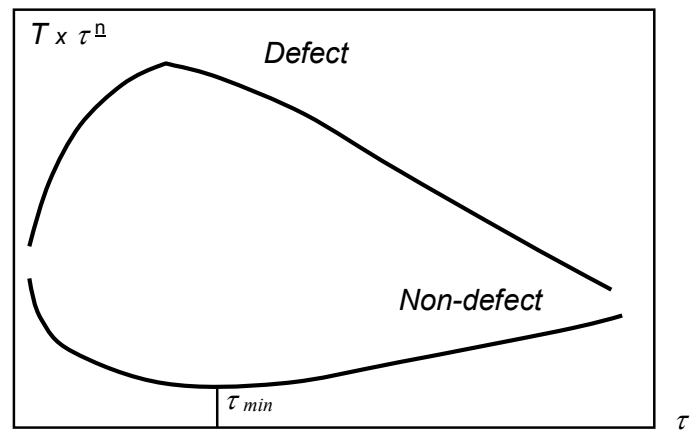

a)

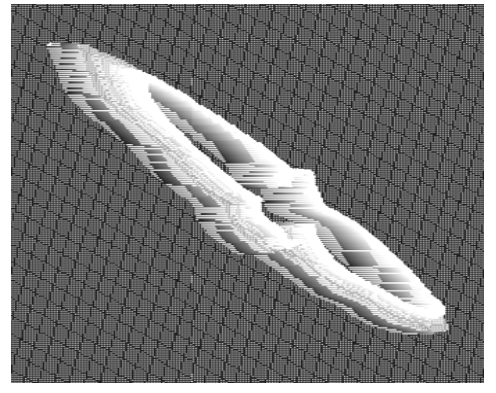

b)

Fig. 2. $T(\tau) \times \tau^{n}$ concept: a) evolution in time, b) reference-free thermal tomogram of impact damage in CFRP 


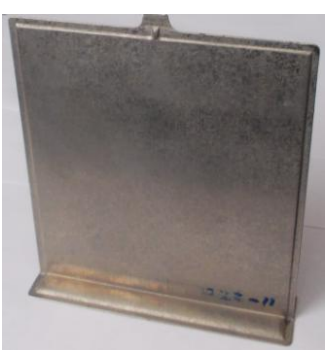

a)

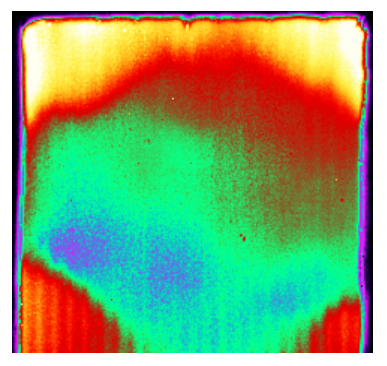

b)

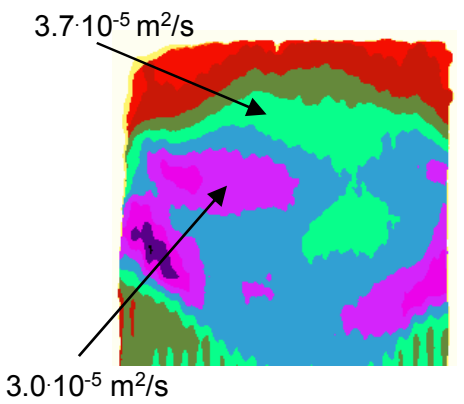

c)

Fig. 3. Pulsed IR thermographic inspection of mini heat tubes: a - mini heat tube, $b$ - best source image,

$$
c \text { - diffusivity map }
$$

Perspective hardware development will involve Western-made components, in particular, IR cores combined with compact heaters thus resulting in a portable TNDT unit, similar to the equipment supplied by Thermal Wave Imaging, Automation Technology, Thermosensorik, Edevis and some other world manufacturers. A key point is supposed to be suppression of additive/multiplicative noise which limits TNDT potentials. The scheme of a thermal tomographic unit which is currently in use is shown in figure 4.

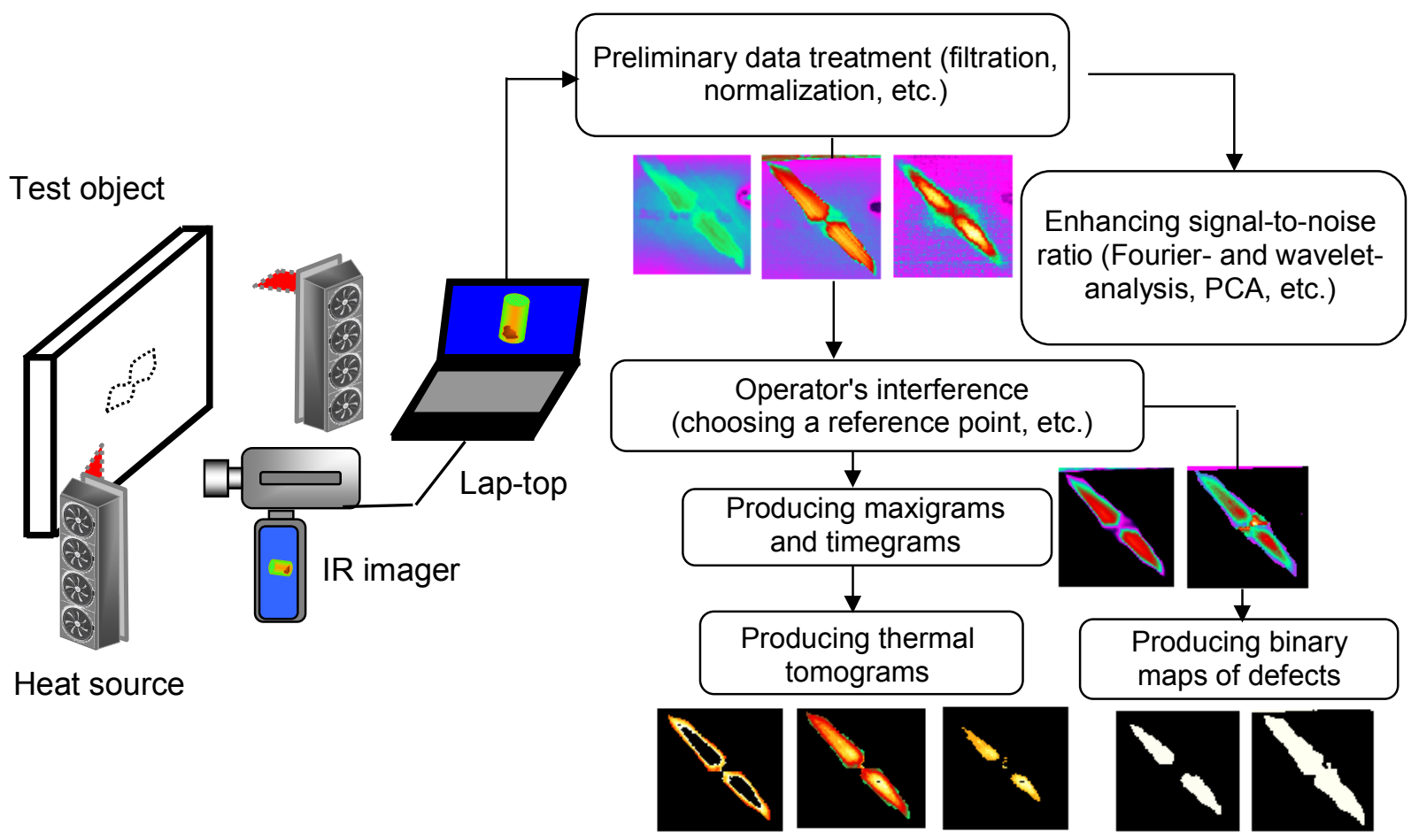

Fig. 4. Thermal tomographic unit for inspecting composites

\section{Acknowledgement}

Since 2014, TNDT research at Tomsk Polytechnic University is being supported by NIR \# 445 (ONG), State order of the Russian Ministry of Higher Education for 2014-2016. 


\section{REFERENCES}

[1] Beller W.S., "Navy sees promise in infrared thermography for solid case checking". Missiles and Rockets, vol. 22, pp. 1234-1241, 1965.

[2] Green D.R., "Emissivity-independent infrared thermal testing method". Mater. Evaluation, vol. 23, No. 2, pp. 7985, 1965.

[3] Vavilov V.P., Gorbunov V.I., Kouznetsov V.B., "Theoretical analysis of thermal NDT of weld spot joints". Defectoscopiya (Rus. J. NDT), No. 1, pp. 21-27, 1973 (in Russian).

[4] Vavilov V., Taylor R., "Theoretical and practical aspects of the thermal NDT of bonded structures". In: Res. Techn. in NDT, ed. by R. Sharpe, London, Academic Press, vol. 5, pp.239-280, 1982.

[5] MacLaughlin P.V., Mirchandani H.G., "Aerostructure NDT evaluation by thermal field detection (Phase II)". Final Rep., AIRTASK, Naval Air System Command AIR-310G. Wash., D.C., U.S.A. 1984.

[6] Carlomagno G. M., Berardi P.G., "Unsteady thermophototopography in nondestructive testing". Proc. 3rd Biannual Exchange, St. Louis, USA, pp.33-39, 1976.

[7] Busse G., "Imaging with optically generated thermal waves". Physical acoustics: Principles and methods, vol. 18, 1985.

[8] Balageas D.L., Krapez J.-C, Cielo P., "Pulsed photo-thermal modeling of layered materials". J. Appl. Physics, vol. 59, No. 2, pp. 348-357, 1986.

[9] Maldague X., "Theory and practice of infrared technology for nondestructive testing". Wiley Series in Microwave and Optical Engineering, New York, John Wiley \& Sons, 2001.

[10] Burleigh D., "A bibliography of nondestructive testing (NDT) of composite materials performed with infrared thermography and liquid crystals". Proc. SPIE "Thermosense-IX", vol. 780, pp. 250-255, 1987.

[11] Vavilov V., Maldague X. "Dynamic thermal tomography: new promise in the IR thermography of solids". Proc. SPIE, "Thermosense-XIV", vol. 1682, pp. 194-206,1992.

[12] Vavilov V., Grinzato E., Bison P.G., Marinetti S., Bales M., "Inversion for hidden corrosion characterization: theory and applications”. Intern. J. Heat \& Mass Transfer, vol. 39, p. 355-371, 1996.

[13] Vavilov V.P., Jin H., Thomas R., Favro L., "Experimental thermal tomography of solids by using pulsed onesided heating”. Defectoscopiya (Rus. J. NDT), No. 12, pp. 122-128 (in Russian).

[14] Vavilov V.P., Burleigh D.D., "Review of pulsed thermal NDT: Physical principles, theory and data processing". NDT \& E International, vol. 73, pp. 28-52, 2015.

[15] Lahiri J., Kuchipudi S., Siddiqui A., Vavilov V., "IR thermographic inspection of filament wound CFRP shell samples". Proc. SPIE "Thermosense-XXIX”, vol. 6541, pp. 65410S1-OS12, 2007.

[16] Guo Xingwang, Vavilov V. P., "Crack detection in aluminum parts by using ultrasound-excited infrared thermography". Infrared Physics \& Technology, vol. 61, pp. 149-156, 2013.

[17] Vavilov V.P., Swiderski W., "Inspecting localized moisture in building materials by applying optical and microwave heating". Proceedings of 9th Quantitative InfraRed Thermography conference, paper QIRT 2008 02_13_14, Krakow (Poland), 2008.

[18] Grinzato E., Vavilov V., Kauppinen T., "Qunatitative infrared thermography in buildings". Energy and Buildings, vol. 29, pp. 1-19, 1998.

[19] Vavilov V.P., "Dynamic thermal tomography: Recent improvements and applications". NDT \& E International, vol. 71, pp. 23-32, April 2015.

[20] Vavilov V.P., Pawar S.S., "A novel approach for one-sided thermal nondestructive testing of composites by using infrared thermography". Polymer Testing, available on-line 4 May 2015, in press, doi:10.1016/j.polymertesting.2015.04.013.

[21] Marinetti S, Vavilov V.P. "Sensitivity analysis of classical heat conduction solutions applied to materials characterization“. Int. J. of Heat Transf. Eng. 2005; 26 (9): 50-60.

[22] Vavilov V.P., Billard S., Ayvazyan A.M. "A thermal tomographic unit for testing composite materials". Rus. J. NDT, vol. 50, No. 11, pp. 71-75, 2014

\section{Appendix. Thermal NDT laws prompted by long-lasting practice}

Law \#1. Any data processing corrupts original data.

Consequence. Any data treatment should be avoided.

Law \#2. Defects which appear as noise should be treated as noise.

Consequence. Most of defects will remain undetected.

Law \#3. The universal noise constant is $0.1^{\circ} \mathrm{C}$.

Consequence. IR imagers having temperature resolution better than $0.1^{\circ} \mathrm{C}$ will not provide better TNDT results. 